\title{
ПСИХОЛОГО-ПЕДАГОГИЧЕСКИЕ ИССЛЕДОВАНИЯ
}

УДК 378.1

DOI: 10.23951/2307-6127-2017-4-158-165

\section{ПЕДАГОГИЧЕСКОЕ ОБРАЗОВАНИЕ В РЕГИОНАЛЬНОМ ОПОРНОМ УНИВЕРСИТЕТЕ: ВЫЗОВЫ СОВРЕМЕННОСТИ И ПОИСК ПУТЕЙ РАЗВИТИЯ}

\author{
А. Л. Гавриков, М. Н. Певзнер, П. А. Петряков
}

Новгородский государственный университет имени Ярослава Мудрого, Великий Новгород

Раскрывается проблема развития педагогического образования в региональном опорном университете на примере Новгородского государственного университета. Показано взаимодействие вуза и региона в подготовке педагога, способного осуществлять свою профессиональную деятельность в условиях информационного общества, цифровизации экономики и образования. Раскрыт опыт сетевого взаимодействия университета с образовательными организациями региона.

Ключевые слова: региональный опорный университет, иифровизачия образования, стратегии развития педагогического образования, взаимодействие вуза и региона, подготовка будущих педагогов в университете.

В современном российском высшем образовании на протяжении ряда последних лет при финансовой и ресурсной поддержке со стороны государства произошли кардинальные изменения в части введения новых стандартов высшего образования, пересмотра структуры направлений и специальностей, состава высших учебных заведений и отнесения их к различным категориям. Эти изменения создали и закрепили в общественном сознании новые условия существования системы высшего образования с проявлением многообразия на институциональном уровне, что нашло свое отражение в различных стратегиях развития российских университетов [1].

В условиях рыночных отношений усиливается конкуренция между вузами за право считаться престижным университетом, относящимся к одной из групп элитных вузов, что способствует расширению институционального многообразия. В структуре вузов России сформированы несколько групп ведущих университетов. В первую группу входят университеты, имеющие особый статус (МГУ, СПбГУ), вторую группу составляют 10 федеральных университетов, а к третьей группе относятся 29 национальных исследовательских университетов. Кроме того, для обеспечения повышения конкурентоспособности на мировом уровне реализуется проект «5-100», в котором участвует 21 университет России. Все названные категории университетов получают существенную государственную поддержку для реализации собственных программ развития.

В целях сокращения межрегиональных различий в развитии экономики и социума и удовлетворения региональных потребностей в квалифицированных специалистах с 2015 г. в российских регионах стали создаваться опорные университеты как драйверы и мозговые центры инновационного развития регионов. В настоящее время насчитывается 33 таких университета, и в дальнейшем планируется расширение сети вузов данной категории. 
Региональные опорные университеты не только обеспечивают местный рынок труда высококвалифицированными кадрами, но и продуцируют научные идеи, направленные на преобразование экономики и культурно-социальной сферы региона, на повышение качества жизни проживающих в нем людей. В текущем году почетный статус регионального опорного университета получил Новгородский государственный университет имени Ярослава Мудрого (НовГУ).

Создание в регионах опорных университетов является частью масштабного проекта реформирования высшего образования в России. Синергетический эффект от создания таких вузов обеспечивается за счет сетевого взаимодействия организаций высшего образования, предприятий и учебных заведений региона, региональных органов власти, объединения их потенциалов, научных баз и кадровых ресурсов. Целью создания такой сети является достижение локальных точек роста и формирование в регионе пространства создания инноваций. Не менее важным является диссеминационный эффект сетевого взаимодействия, поскольку опыт, накопленный опорными университетами, представляет ценность не только для одного региона, но и является объектом диссеминации во многие регионы России, имеющие сходные социокультурные условия.

Процесс становления региональных опорных университетов в России освещен в работах таких авторов, как Р. Г. Буянкина, Р. А. Зуков, Н. А. Князев, А. В. Навроцкий, Л. С. Шаховская, И. Л. Гоник, О. В. Юрова и др. [2-4]. Большинство опорных вузов уделяют основное внимание модернизации инженерно-технического образования, реализации основных направлений национальной технологической инициативы (НТИ), завоеванию лидерских позиций как центра технологического развития региона. В программах стратегического развития опорных университетов акцент часто делается на внедрение модели развития вузов, предполагающей не только генерацию новых знаний через исследовательскую деятельность, но и предпринимательскую активность преподавателей и студентов, коммерциализацию технологий, создание компаний, внедрение ценностей, связанных с активным развитием технологической и предпринимательской экосистемы вуза. При реализации такой модели часто не учитывается, что достижения технологических прорывов во многом зависят от качества подготовки педагогов, способных сформировать у выпускников образовательных организаций компетенции, необходимые для инновационного развития территорий.

В этом контексте особо актуальным становится поиск стратегий развития педагогического образования в региональных опорных университетах, которые могут быть использованы в других регионах России и адаптированы с учетом местных социокультурных условий. При этом должен быть решен ряд проблем, накопившихся в системе педагогического образования регионального университета, главной из которых является отсутствие практико- и проектоориентированности университетского образования будущих учителей, содержание которого продолжает оставаться отчужденным от реальной образовательной практики, не сориентированным на удовлетворение новых запросов образовательных организаций и других субъектов регионального рынка образовательных услуг.

Размышляя о дальнейших путях развития педагогического образования в региональном опорном университете, мы должны отчетливо представить, что выпускник педагогического профиля будет работать в мире, кардинально изменяющемся под влиянием информационной революции, и взаимодействовать с детьми, принадлежащими к новому «цифровому поколению».

В современном обществе меняются технологический и экономический уклады, массовым явлением становится цифровизация экономики, социальной жизни и образования. Новые технологии создают неосвоенное пространство, в котором достаточно быстро 
уходят в небытие прежние профессии, а взамен появляются в еще большем многообразии новые квалификации на стыке цифровых и материальных технологий, нано- и биосистем. Сегодня высокая технологическая революция в сфере искусственного интеллекта коренным образом может изменить повседневную практику жизни и деятельности людей. В мире информационных технологий начинает доминировать рынок компьютерных игр, систем дополненной реальности, который может составить основу развития целой территории. Цифровые навыки и компетенции, являясь движущей силой развития инноваций и конкурентоспособности страны, меняют и педагогическую профессию, требования к цифровой квалификации учителя. Несомненно, учитель всегда был и остается живым источником знаний, и его задача - передать эти знания ученикам. Однако в современном информационном обществе принципы, на которых основано образование, начинают существенно меняться. Каждый обучающийся сегодня может осваивать онлайн-курсы, самостоятельно находить информацию на любые темы, посещать виртуальные музеи и выставки, пользоваться дистанционно открытыми библиотечными источниками и архивами. Главное, что теперь требуется от учителя, - научить школьника учиться. Меняются и подходы к методике преподавания: акцент делается на способы поиска нужной информации и подбор поисковых ресурсов, развитие навыков тайм-менеджмента, привитие знаний по цифровой безопасности. Об этом много говорилось на прошедшей 2627 сентября 2017 г. в Санкт-Петербурге международной конференции по новым образовательным технологиям EdCruch-2017 [5].

Вместе с тем при проектировании модели педагогического образования в региональном опорном университете следует обратить внимание и на оборотную сторону яркого футуристического фасада образования будущего. Если раньше человек непосредственно воздействовал на природу, создавал машины для производства продуктов потребления, настраивая на этот узкоспециализированный процесс профессиональную структуру и профессиональное образование, то с появлением универсальных средств производства и коммуникаций у человека появился посредник в виде искусственной среды обитания. Таким образом, появилась новая культура на основе совокупности технологий. Сегодня многие понятия, определения и характеристики, которые раньше относились только к человеку, стали переноситься на технические устройства и программные комплексы. Если раньше мы говорили «умный человек», «умный ребенок», то теперь понятия «умный город», «умная школа», «умный дом» становятся языковой нормой применительно к высокотехнологичному окружению человека. Интернет вещей уже становится средством существования высокоинтеллектуальной искусственной среды обитания самого человека. Все эти факторы, будучи вызовом для развития регионального опорного университета в целом, должны быть учтены при подготовке педагога.

В современном мире проявляется частичное отождествление социальности и техники, социальности и компьютерной коммуникации, техники и знания. Тотальная власть техники имеет сегодня мощное мировоззренческое влияние на все сферы социальной жизни. В этих условиях особенно важно правильно оценить роль и значение новой среды обитания для человека. Преувеличение этой роли носителями технологических новаций приводит к ложному очеловечиванию и замене человека как социального и культурного субъекта техническим устройством. При подготовке педагога важно опережающим образом закрепить и обосновать представление о том, что при всем комфорте и технологической оснащенности современной среды за человеком остается ответственное право выбора принимаемого решения. Философское осмысление последствий своей деятельности, в том числе по применению тех же высокоинтеллектуальных технических средств, программных систем, новых 
нано- и биоматериалов, когнитивных технологий останется за человеком, и он будет нести ответственность за результаты своей деятельности. Будущему педагогу предстоит учить этому своих воспитанников.

В ближайшее время учитель может столкнуться еще с одним нравственным аспектом процесса педагогического взаимодействия, который лежит в плоскости защиты прав и свобод персональных данных учащегося. Опасность подавления таких свобод можно проиллюстрировать на примере все большего распространения технологий больших данных (big data). Речь идет уже не о технологии, а об инструменте социального управления (и, возможно, манипулирования). Появление в рамках поисковых систем Yandex и Google систем продвижения информационных ресурсов и коммерческих продуктов на основе изучения индивидуализированных предпочтений миллионов пользователей Интернета заставляет сегодня говорить об угрозах интересам личности. Суть в том, что при взаимодействии с пространством Интернета человек порождает множество «окрашенных» потоков специфической информации о самом себе. Таким образом, неявным образом формируется достаточно полный портрет личности, включая и внутренние психофизиологические особенности (время реакции, усталость, время бодрствования и отдыха и т. п.), конкретного человека без его на то согласия. Перенос этих технологий на образовательную сферу вполне возможен. Положительной стороной такого переноса является возможность направить усилия учащегося на решение учебных задач с учетом его скрытого личностного потенциала. Вместе с тем в процессе подготовки учителя необходимо проводить профилактику возможных злоупотреблений использования сугубо личной информации против воли ученика и его родителей.

Здесь уместно обратить внимание на наставление о сходстве миссии священника и учителя, высказанное в приветственном выступлении епископа Юрьевского Арсения на августовской педагогической конференции, проходившей в 2017 г. в Великом Новгороде. Ученик неявным образом, участвуя в компьютеризированном обучении с потоковым сбором данных, находится в состоянии «исповеди», а учитель оказывается принимающим исповедь духовным наставником. Это уже другая и более ответственная роль, скорее, миссия, для исполнения которой нужен более тщательный отбор и формирование новых критериев и компетенций в подготовке учителя. В нравственной плоскости находится также и вопрос сохранения «тайны исповеди» - педагогически важной, но глубоко личной, персонифицированной информации об ученике, и принятия на себя обязательства о неразглашении и неиспользовании этой информации во вред ученику, что является близким к клятве Гиппократа, которую дают врачи, приступая к врачеванию.

С учетом нравственных, философских, мировоззренческих аспектов профессиональной деятельности современного педагога подготовка учителя в опорном региональном университете должна осуществляться системно. Серьезных изменений требует проведение педагогической практики, которая должна стать более продолжительной по времени и многооаспектной по содержательному наполнению, что позволит студентам в период обучения приобрести первичный опыт реальной профессиональной деятельности в различных образовательных средах региона. Расширению базы практик будет содействовать развитие сетевого взаимодействия в регионе образовательных организаций разных уровней. Так, НовГУ в настоящее время как опорный региональный университет тесно сотрудничает со многими школами региона, используя такие формы работы, как физико-математический лекторий, летняя школа по программированию, вебинары для школьников и учителей, лектории по историко-культурным направлениям.

Программа развития НовГУ как опорного вуза предусматривает создание новых агентов влияния университета в региональном образовательном пространстве. Речь идет о фун- 
кционировании физико-математической и медико-биологической школ, Малой академии гуманитарных наук и права, в составе которой будут действовать несколько школ: школа юного криминалиста, школа юного журналиста, школа юного историка и археолога, школа юного словесника, школа юного культуролога. Университет планирует привлечь к занятиям в Малой академии госуправления учащихся 11-х классов всех школ Великого Новгорода в очной форме, а учащихся школ районов области в онлайн-режиме.

В рамках сетевого взаимодействия с образовательными организациями региона НовГУ использует в образовательном процессе проектные технологии, направленные на формирование у студентов умений по разработке социально значимых проектов, востребованных на региональном рынке образовательных услуг и конкурентоспособных при проведении российских и региональных конкурсов продуктов проектной деятельности учащейся молодежи.

При определении путей развития современного педагогического образования следует преодолеть его одностороннюю ориентацию на учебную деятельность и усилить подготовку студентов к воспитательной работе в школе. Поэтому в НовГУ внедряется целый ряд практико-ориентированных курсов, связанных с методикой воспитательной деятельности, досуговой педагогикой, семейным воспитанием, большое внимание уделяется психологопедагогическому консультированию учащихся и их родителей. Выпускники педагогического профиля овладевают арсеналом педагогических средств, позволяющих им компетентно актуализировать потенциальные воспитательные возможности культурно-исторической среды региона, используя при этом технологии и методики этнопедагогики, музейной педагогики и образовательного туризма.

В этом контексте трудно переоценить воспитательное значение исторического опыта Великого Новгорода с его традициями демократического самоуправления, интеграции в европейскую экономику, первыми центрами грамотности, высокой духовной и материальной культурой. Изучение этого опыта студентами педагогического профиля способствует формированию у них и их будущих учеников социальной памяти, которая является основой национальной и личностной культуры нации. Здесь справедливо привести мнение Ч. Айтматова: «Человек без памяти прошлого, поставленный перед необходимостью заново определить свое место в мире, человек, лишенный исторического опыта своего народа и других народов, оказывается вне исторической перспективы и способен жить только сегодняшним днем» [6, с. 197-198].

Духовному развитию будущих педагогов в НовГУ способствует Всероссийский научно-образовательный духовно-просветительский комплекс «Антоново», основной задачей которого является расширение возможностей осуществления патриотического воспитания и совершенствования подготовки специалистов с углубленным изучением истории, теологии, искусствознания, регионоведения, литературы и языка [7]. Часть занятий с будущими педагогами проходит в университетском музее русской письменной культуры и книжности, в разделах экспозиции которого представлены новгородские летописи, книги Священного Писания, копии сюжетных миниатюр летописных сводов, заглавные листы памятников древнерусской письменности, агиографическая литература, копии берестяных грамот и другие материалы, представляющие собой не только историческую, но и педагогическую ценность.

Сегодняшний выпускник регионального опорного университета должен быть готов к решению сложных профессиональных задач, связанных с расширением спектра педагогической деятельности в регионе и дифференциацией профессионально-педагогических ролей. Поэтому студенты должны получить возможность приобрести в университете необходимые дополнительные компетенции, обеспечивающие их успешную профессиональную 
деятельность в сфере образования взрослых, обучения лиц третьего возраста, в системе дополнительного образования детей и подростков. В связи с этим НовГУ планирует внедрить технологии проектирования и реализации образовательных программ с использованием модулей «майнор» (minor), расширяющих профиль формируемых компетенций в интересах реального сектора экономики и рынка образовательных услуг. Предполагается, что будущие учителя естественно-научных предметов, информатики и технологии смогут пройти практику в детском технопарке «Кванториум», который недавно открылся в Великом Новгороде и активно сотрудничает с НовГУ в рамках сетевого взаимодействия.

При консультативной поддержке ученых НовГУ «Кванториум» проводит сегодня занятия со школьниками по четырем направлениям: «Ні-Тесh», где школьники могут познакомиться с технологиями прототипирования, «ІТ-квантум», в котором постигаются основы программирования, «Энерджиквантум», который знакомит школьников с различными аспектами дизайна и маркетинга, четвертое направление рассматривает проблемы дополненной и виртуальной реальности. В «Кванториуме» у школьников с помощью ученых НовГУ формируется изобретательское и продуктивное мышление, развивается умение работать в команде, осваивается технология постановки задач и проектное управление.

Как отмечают А. В. Навроцкий, Л. С. Шаховская, Я. С. Матковская, университет меняется под потребности региона, но при этом меняется и сам регион, увеличивается его интеллектуальный потенциал, что проявляется в повышении качества региональных человеческих ресурсов [4]. В настоящее время НовГУ проектирует и апробирует наиболее эффективные пути развития педагогического образования в региональном опорном университете, отвечающего современным требованиям общества, работодателей и профессиональноличностным запросам студентов - будущих педагогов, направленного на подготовку компетентных выпускников, востребованных в современной системе образования российских регионов.

Обращаясь в будущее и формулируя новые стратегические цели развития педагогического образования, авторы опираются на миссию НовГУ, в которой заявлено его предназначение «во всемерном развитии образования и науки в интересах личности, общества и государства, в прославлении земли Новгородской ученостью и соборностью», намерение «поспособствовать развитию технологической и предпринимательской экосистемы» и «осуществить интеллектуальное сопровождение в научной, образовательной, социально-культурной и производственной сферах», а также выражена уверенность в том, что университет станет «привлекательным для талантливой молодежи» и поможет сделать Новгородскую землю «обучающимся, инновационным и конкурентоспособным регионом с высоким уровнем инвестиций в развитие человеческого потенциала и гармонично взаимодействующим с российским и зарубежным образовательным, научным и культурным сообществом» [8].

\section{Список литературы}

1. Криштал М. М., Ельцов В. В., Комягин А. В. Формирование и реализация стратегии развития вуза как фрактор экономической стабильности и качества образовательного процесса // Инженерное образование. 2016. № 19. С. 111-115.

2. Буянкина Р. Г., Зуков Р. А., Князев Н. А. Философские основания регионального развития опорных университетов // Вестн. Новосибирского гос. пед. ун-та. 2016. №5. С. 116-129.

3. Гоник И. Л., Юрова О. В., Теткин А. В., Стегачев Е. В., Фетисов А. В. Модернизация системы управления как инструмент развития регионального опорного университета // Высшее образование в России. 2016. № 7. С. 117-126.

4. Навроцкий А. В., Шаховская Л. С., Матковская Я. С. Роль опорных региональных вузов в социально-экономическом развитии российских территорий // Известия ВолгГТУ. Волгоград, 2017. С. 8-15.

5. Профессиональные знания и умения педагога в условиях цифровой экономики. URL: http://2017.edcrunch.ru/program/ section/31. 
6. Айтматов Ч. Сборник сочинений: в 3 т. Т. 2. Повести. Роман. М.: Молодая гвардия, 1983. С. 197-198.

7. Вебер В. Р., Гавриков А. Л. Воспитательная миссия университета // Образование: цели и перспективы. 2015. № 41. C. $214-219$.

8. Миссия Новгородского государственного университета имени Ярослава Мудрого. URL: http://www.novsu.ru/dept/1106/ i. $804531 / ? \mathrm{id}=804557$.

Гавриков Анатолий Леонидович, доктор социологических наук, профессор, Новгородский государственный университет имени Ярослава Мудрого (ул. Большая Санкт-Петербургская, 41, Великий Новгород, Россия, 173003). E-mail: Anatoly.Gavrikov@novsu.ru

Певзнер Михаил Наумович, доктор педагогических наук, профессор, Новгородский государственный университет имени Ярослава Мудрого (ул. Большая Санкт-Петербургская, 41, Великий Новгород, Россия, 173003). E-mail: Mikhail.Pevzner@novsu.ru

Петряков Петр Анатольевич, доктор педагогических наук, доцент, Новгородский государственный университет имени Ярослава Мудрого (ул. Большая Санкт-Петербургская, 41, Великий Новгород, Россия, 173003). E-mail: pap15@yandex.ru

Материал поступил в редакиию 05.09.2017

DOI: 10.23951/2307-6127-2017-4-158-165

\section{PPEDAGOGICAL EDUCATION IN THE REGIONAL FLAGSHIP UNIVERSITY: CHALLENGES OF THE PRESENT AND THE SEARCH FOR WAYS OF DEVELOPMENT}

\section{A. L. Gavrikov, M. N. Pevzner, P. A. Petryakov}

Yaroslav-the-Wise Novgorod State University, Veliky Novgorod, Russian Federation

The article reveals the features of flagship universities as drivers and think tanks of innovative development of regions. Regional flagship universities provide the labor market with highly qualified specialists, produce scientific ideas aimed at transforming the economy and socio-cultural sphere of the region, improving the quality of life of the population. The authors reflect on the effective ways to develop pedagogical education in a regional flagship university that meets the modern requirements of society, employers and professional and personal needs of students - future teachers, aimed at training competent graduates in demand in the modern education system of Russian regions. The article is devoted to the search for strategies for the development of pedagogical education in regional flagship universities, which can be used in various regions of Russia, taking into account the peculiarities of their sociocultural conditions. The interaction of the university and the region in the training of teachers able to carry out their professional activities in the conditions of the information society, the digitalization of the economy and education is shown. Particular emphasis is placed on the need to strengthen practical and project-oriented training of future teachers, more effective pedagogical practice, which allows students to acquire the primary experience of a real professional activity in various educational environments of the region. The authors of the article pay great attention to the problem of network interaction between the university and the educational organizations of the region, the use of design technologies in the educational process aimed at building students' skills in the development of socially significant projects that are in demand on the regional market of educational services. The article points out the need to strengthen the training of students for educational work in the school, as well as the actualization of the potential educational opportunities of the cultural and historical environment of the region with the use of methods and technologies of ethnic pedagogy, museum pedagogy and educational tourism. The article notes the importance of acquiring additional competencies by the graduates of the regional flagship university, en- 
suring their successful professional activity in the field of adult education, the training of people of the third age, in the system of additional education for children and adolescents.

Key words: regional flagship university, digitalization of education, strategies for the development of pedagogical education, interaction between the university and the region, training future teachers at university.

\section{References}

1. Krishtal M. M., El'tsov V. V., Koryagin A. V. Fornirovaniye i realizatsiya strategii razvitiya vuza kak factor ekonomicheskoy stabil'nosti I kachestva obrazovatel'nogo protsessa [Formation and realization of strategy of development of the University as a factor of economic stability and quality of the educational process]. Inzhenernoye obrazovaniye - Engineering education, 2016, no. 19, pp. 111-115 (in Russian).

2. Buyankina R. G., Zukov R. A., Knyazev N. A. Filosofskiye osnovaniya regional'nogo razvitiya opornykh universitetov [Philosophical foundations of regional development of flagship universities]. Vestnik Novosibirskogo gosudarstvennogo pedagogicheskogo universiteta - Novosibirsk State Pedagogical University Bulletin, 2016, no. 5, pp. 116-129 (in Russian). DOI: 10.15293/2226-3365.1605.08.

3. Gonik I. L., Yurova O. V., Tetkin A. V., Stegachev E. V., Fetisov A. V. Modernizatsiya sistemy upravleniya kak instrument razvitiya regional'nogo opornogo universiteta [Modernization of the management system as a tool of regional development support of the University]. Vyssheye obrazovaniye $v$ Rossii - Higher Education in Russia, 2016, no. 7, pp. 117-126 (in Russian).

4. Navrotskiy A. V., Shakhovskaya L. S., Matkovskaya Ya. S. Rol' opornykh regional'nykh vuzov v sotsial'no-ekonomicheskom razvitii rossiyskikh territoriy [The Role of supporting regional universities in socio-economic development of Russian territories]. Izvestia VolgGTU - Izvestiya VSTU, 2017, pp. 8-15 (in Russian).

5. Professional'nye znaniya i umeniya pedagogov $v$ usloviyakh tsifrovoy ekonomiki [Professional knowledge and skills of the teacher under the conditions of digital economy] (in Russian). URL: http://2017.edcrunch.ru/program/section/31.

6. Aytmatov Ch. Sbornik sochineniy: $v 3$ tomakh. T. 2. Povesti. Roman [A Collection of essays: in 3 volumes. V. 2. Stories. Novel. Moscow, Molodaya gvardiya Publ., 1983. Pp. 197-198 (in Russian).

7. Veber V. R., Gavrikov A. L. Vospitatel'naya missiya universiteta [The Educational mission of University]. Obrazovaniye: tseli I perspektivy - Education: goals and prospects, 2015, no. 41, pp. 214-219 (in Russian).

8. Missiya Novgorodskogo gosudarstvennogo universiteta imeni Yaroslava Mudrogo [The mission of the Novgorod State University named after Yaroslav the Wise]. URL: http://www.novsu.ru/dept/1106/i.804531/?id=804557 (in Russian).

Gavrikov A. L., Yaroslav-the-Wise Novgorod State University (ul. Bolshaya Sankt-Peterburgskaya, 41, Veliky Novgorod, Russian Federation, 173003). E-mail: Anatoly.Gavrikov@novsu.ru

Pevzner M. N., Yaroslav-the-Wise Novgorod State University (ul. Bolshaya Sankt-Peterburgskaya, 41, Veliky Novgorod, Russian Federation, 173003). E-mail: Mikhail.Pevzner@novsu.ru

Petryakov P. A., Yaroslav-the-Wise Novgorod State University (ul. Chudintseva, 6, Veliky Novgorod,Russian Federation, 173003).E-mail: pap15@yandex.ru 